\title{
THE SMARTPHONE IN THE CONTEXT OF THE CLASSROOM IN THE PRIMARY SCHOOL AND IN THE HIGHER EDUCATION
}

\author{
Paula Quadros-Flores ${ }^{1}$, Antonio Flores ${ }^{2}$, Altina Ramos ${ }^{3}$ \\ ${ }^{1}$ Polytechnic Institute of Porto, High School of Education (PORTUGAL) \\ ${ }^{2}$ Polytechnic Institute of Porto, Higher Institute of Engineering of Porto (PORTUGAL) \\ ${ }^{3}$ University of Minho (PORTUGAL)
}

\begin{abstract}
Information and Communication Technologies (ICT) are implementing unique changes in the most diverse fields nowadays. The smartphone, in particular, because of its technological convergence characteristics and because it is a tool that everyone owns and carries with them, it is an added value for the school and for the student that owns a personalized mobile resource. However, the school is resistant to its inclusion in education and there are contradictory studies: some reveal perverse effects on education, but others show their potentialities [1-3]. This fact shows the importance of teacher training in the selection of a methodology that responds to the inclusion of this tool in education. How to use the smartphone in education? It is a challenge that we intend to answer by showing the potential of this emerging technology in the process of teaching and learning with children from 6 to 9 years of age (primary school) and with adults of higher education (engineering course). In this study, the use of smartphones was observed in three classrooms of the primary school, involving about 60 children, and in higher education classes, involving about 50 students. We used a qualitative approach, case study. Data were collected from direct observers of the educational practices in the different contexts. For data analysis, we used description and data interpretation.
\end{abstract}

The results show that teachers adopt a socio-constructivist methodology centring the student in the learning process: (1) in the use of the tool (technical domain), (2) in the accomplishment of the task, (3) in the reflection and argumentation of the results obtained, (4) knowledge sharing, (5) behaviour management, attitudes, task leadership and (6) self-criticism. It is also verified that they use the smartphone as a resource to motivate the student, stimulate concentration on the task, facilitate the understanding of content, encourage participation in the activity and promote interaction and sharing with others. In addition, the use of smartphones generates emotions and develops cross curricular skills in education as well as facilitating access to information, stimulates the creation of creative engineering projects that have satisfied students not only for the novelty, but also for finding that a pocket tool can perform interesting monitoring and remote control tasks. Thus, the results show that smartphones have a high potential in education, as they can promote an opportunity for methodological recreation and modernization, offer research potential, the development of new educational equipment and tools, new ways of consolidating and evaluating curricular content, development of other expressive abilities in the academic, social and personal life of an individual, as well as develop autonomy and stimulate the satisfaction of the students by returning to education the motivation of the student. It is also a clever way of educating this new generation by finding other ways of learning to learn, learning to do and building knowledge, learning to be and being with others.

Keywords: Innovation, Initial teacher education, ICT, Smartphone, Methodological renewal.

\section{INTRODUCTION}

Transform, Recreate, Innovate: the three keywords of a changing world! The current conjecture of technological development, namely the easy access of the Internet on mobile devices, allows us to work in a different way also in the field of education, but it requires a proactive attitude of developing skills, updating knowledge, abilities and educational resources, requires a student profile for the $21^{\text {st }}$ century [4] and a common benchmark of digital teacher competence [5].

It also demands on the part of the teacher an attitude of deconstruction and reconstruction of methodologies appropriated to the era of the digital culture, for which it imposes flexibility, adaptability, creativity, resilience and entrepreneurship. It also imposes moments of lifelong training [6] by reflective practice [7] and reflexive thinking [8] to deal with uncertainty, and research-action methodologies [9] to improve pedagogical practices. The teacher must, as Carneiro says [10], give opportunities for each one to assume his own responsibility [6] in the process of learning and building knowledge. 
The initial teacher education has a close eye on the changing needs, demanded by the characteristics of the native digital generation, as Prensky points out [11], but it avoids "disruptive innovation because it is a challenge of radical transformation of traditional cultures" (196) and because it requires prior research, prior to implementation in contexts. Unless it is an isolated project, according to the authors [12] (p.106) "innovation must be gradual even because it involves school teachers often with traditional conservative and inflexible practices".

In the context of the use of mobile devices in Portuguese schools, there has been a lot of resistance, due to the lack of rules of their use in this context, but also because of the harmful effect on the students causing distraction [13], high risk and inattention [14]. Also Chad C.Tossell, Philip Kortum, Clayton Shepard, Ahmad Rahmati and Lin Zhong [15] show that access to mobile technology alone is insufficient to improve student performance, although ubiquitous access to information and communication can bring opportunities for informal learning (not valued at school) and benefit other situations [16], reinforces the added value by the opportunity to access information without constraint of time and space. Thus, several authors refer to the positive power of mobile technology, recommending their integration in an educational context, so that the reflection on this theme emerges to find pedagogical paths since the tool motivates children, and motivation is the master key in the learning process.

In the context of higher education, Parmigiani and Giusto [17] show that mobile devices are useful to develop learning, if used in a structured way, developing good quality digital creation opportunities in a cooperative, collaborative and reflective process, and avoid being only used for access to information without the students having the opportunity to develop deep and complex learning. Vázquez-Cano \& García [18] state that they are used in academic information exchanges, coordination of group work and consultation and university services.

Regarding primary and secondary education, Adelina Moura, [19] points out that there are still cases of banning smartphones from entering school; in her case, however, they are used to learn, for example to record and consult relevant content. According to the author, the students who usually register the information in the smartphone, are the ones that always have it available. She also mentioned a smartphone contest in which students received SMS (Short Messages) from the teacher with multiple-choice questions. It was found that in the first five minutes more than $50 \%$ responded immediately. In addition, she often sent them audio Podcasts with the subject summary to improve their listening skills of a foreign language. She states that "mobile learning dilutes the boundaries of the classroom, and learning can continue after school, at home, on the street, on the bus..." so we have to give students the opportunity to use pedagogically in the classroom mobile technologies. The example of this teacher reveals the importance of the teacher's attitude to the obstacles of the context, but also that the use of a technology involves adapting the tool to the teaching model by recreating it, broadening the objectives and the opportunities, making the smartphone as an element of pedagogical mediation. A new educational paradigm emerges, based on mobile learning, or m-learning [20], since the learning process is supported by the communication and connection potentialities of a type of mobile technology that allows student mobility, as never happened, creating learning opportunities in different contexts and times, and user-driven learning. Carvalho and Araújo [21], referring to a project in the scope of a foreign language, concluded that students $\left(3^{\text {rd }}\right.$ cycle) used the smartphone with instructional guidance on average 6.5 hours per week, probably longer than they would have spent on study without this tool and that the student learns with satisfaction and this contributes to the success in education. Klopfer [22] refers to very relevant game structures in learning experiences: decisions with consequences, clearly defined goals, and visible feedback underlying a model.

\section{METHODOLOGY}

An approach of qualitative nature, the exploratory study, was chosen. This type of study "applies to realities not yet studied or unknown in order to increase the familiarity of the researcher with an environment, fact or phenomenon" [23] (p. 190). Familiarity with the phenomenon, having a small sample, arise from the curiosity of the researcher, are reasons that, for this author, justify the exploratory study.

\subsection{Data Collection and analysis}

In order to understand how the smartphone is used in the context of primary education and higher education, we opted for direct observation in a classroom context, so this article reports the direct 
voices of observers who witnessed the experiences in both educational contexts. Thus, with regard to the First Cycle of Basic Education, the observer, institutional supervisor, helped in designing the lesson plans elaborated by students in initial teacher training, in a situation of internship, and watched its application during the class in real context.

Regarding higher education, the observer, professor of the discipline, reports on the way the smartphone was used by a group of engineering students with two functions: as a resource to support classes, like a computer, allowing easy and quick access to a repository of support materials; as a pedagogical instrument that allows to test the assemblies of electrical circuits supported by simulators made available in smartphones and that stimulates the creation of innovative electrotechnical projects by the forms of communication that facilitate the user-machine interface.

\section{ANALYSIS AND DISCUSSION OF RESULTS}

To better understand the results of this study, we present initially educational practices whose use of the smartphone was an added value in the teaching and learning process. Then we will analyse and discuss results regarding the methodology used and its impact on the students' training process.

\subsection{The smartphone in primary education}

"An education can only be sustainable if it is an integral education of the human being. An education that addresses the open totality of the human being and not just one of its components" [24] (p. 11), because fragmentation prevents the flow between the parts and the totality and there is a need to replace it with a knowledge that integrate the objects in context [25]. In fact, the human being is built in social life and learning is a resource of this construction [26], so education should not ignore the emergence of new educational resources that carry a new cycle of change in an old educational context that is kept up to date and increasingly reinforced by the generalist idea of primary education, globalization, of the responsibility of a single teacher [27] that emphasizes transdisciplinarity as the support of the articulation and construction of knowledge, without diminishing the specificity of each of the knowledge linked to different curricular areas. The momentum of today's technology has allowed the integration of various resources into a single object, such as the smartphone, making it a smart and fundamental tool for design a new look at how teachers teach how to learn and how does children learn. Indeed, we could verify, in the specific case of primary education that the object "smartphone" that walks daily in the children's pockets to school, is, in a school context, a device that favours transdisciplinarity and meaningful learning when integrated in active methodologies and innovative approach. In this context, it is stressed that teachers need to study strategies that address obstacles such as lack of technological resources, that is, "they need to articulate solutions that enable transformative strategies that integrate different objectives and action plans". It will be exemplified with some examples:

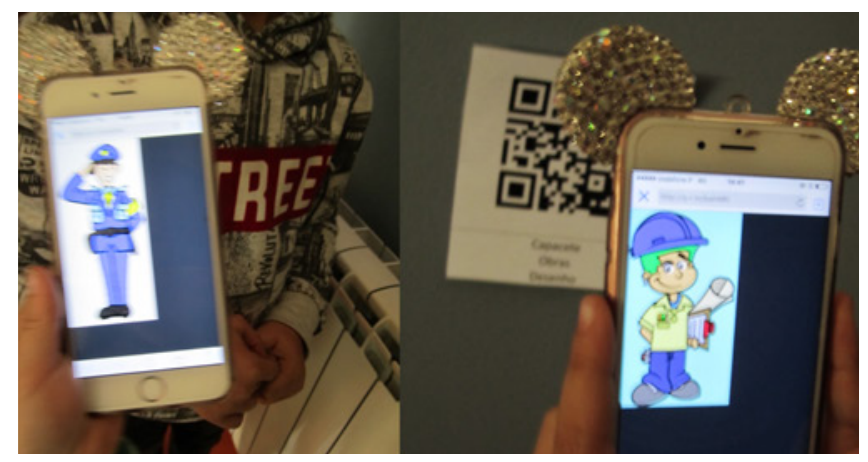

Fig. 1. The smartphone in the discovery of the professions.

Contextualization: Heterogeneous group, with children who present difficulties of concentration, and enjoy using technology.

Curricular articulation: Study of the Environment, Portuguese (orality), ICT, Citizenship, Dramatic Expression.

Motivation: Using QrCode to discover images related to various professions. 
Development: The children watch a movie "Quinó, the ball player" that involves the professions desired by the children of the class. During the discussion, they are invited to visit, in a row, an exhibition of QrCodes on the walls of the classroom. They access the information (pictures about the professions) using a smartphone, having to choose one of the professions to present (mimic gesture) to their colleagues. During the presentation, the student should be clear in expressing the characteristics of the profession and in the discussion with the colleagues should know how to present characteristics and opinions about the professions and argue during the discussion phase.

In this case, the teacher supervisor of the school reinforces the articulation of knowledge that the strategy involved and above all that "the trainee teacher has overcome the problem of lack of resources by dividing the class into small groups of children using smartphones of their fellow trainees". In the class he emphasized "the participation of all the children, especially the interest in the activity and the desire to do it", "the enthusiasm was remarkable for the children, but also (there was) satisfaction of the trainee teacher."

Regarding the search for questions that promote understanding of the text (Fig. 2), the trainee teacher divided the class into two groups, each of which addressed its theme. In one group, the children used the smartphone to read the guiding questions of understanding the text of a study animal and complete a chart with creative phrases. In the other group, the children read a text, which they dramatized next, having, one of the children used the smartphone to aid their role of director producing a small film. Then the film produced was presented to the group to be discussed and in this discussion the children were shown to be participative and reflective.

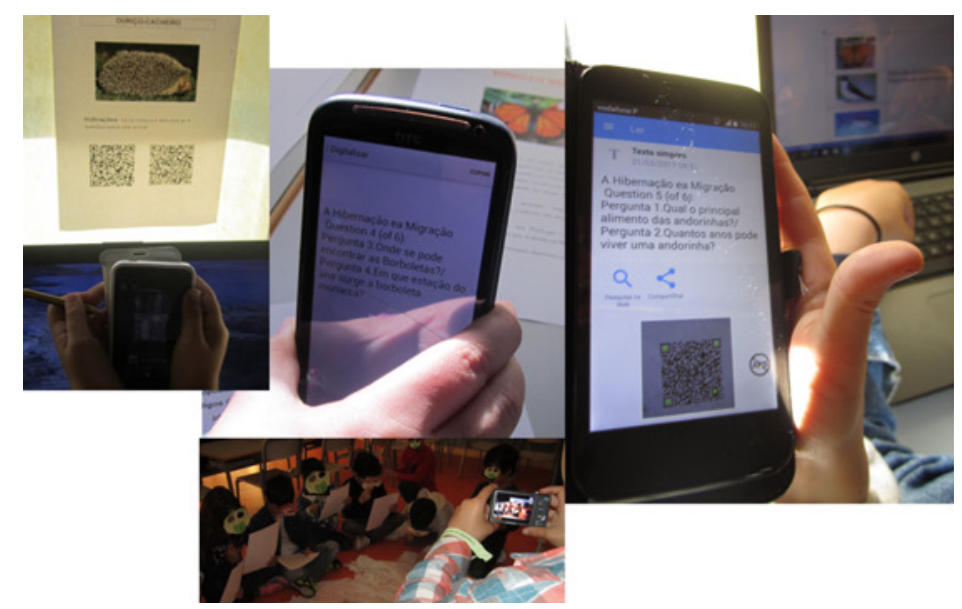

Fig. 2 The smartphone in the pursuit of questions that promote understanding of the text.

According to the supervisor "the children were very participative, even the most timid, and it was found that reading in technological support also requires some training, because it was found that children who read well in the school manual did not read as quickly and expressiveness on the smartphone. This means that the school should be given opportunities to read on different media". With regard to filming and analysis of the film "to note the opportunity that the school gives the child to perform tasks other than the curriculum, but also to self-regulate through self and hetero-evaluation". As for the teacher, it was found that "he was more available to meet the children's difficulties, but equally satisfied".

Contextualization: There was a need to develop dynamic group activities to stimulate collaborative work and develop social and interpersonal skills.

Curricular articulation: Study of the Environment, Portuguese (orality), ICT.

Motivation: The class is divided into two large groups. One group uses their smartphone to access, through QrCode, questions that support understanding of a text and are important for building children's creative sentences in Word. The other group uses the smartphone to film the dramatic representation of a text for later reflection.

In Fig 3, we see the smartphone as a consolidation tool involving different curricular areas. Children are using Kahoot which is is a simple application that allows you to include a quiz in the game stimulating collaborative learning. According to the trainee supervisor, "it brings back to school moments of pleasure and contagious enthusiasm, and it requires immediate thinking, spontaneous 
reaction and balanced group dynamics in the collaborative process". When the smartphone is used "the children check the exercises they performed and release the teacher for other functions. They enjoy this autonomy and feel self-confident with the tool. "This resource is used as a learning tool, that is, "children refer words they have learned and these are recorded to be used as a dictation support".

It should be noted that in primary education the majority of children in this age group (from 6 to 9 years) do not bring smartphones to school, but the trainee teacher carries several smartphones with him to carry out the activities in the classroom. It was verified that the smartphone facilitated the articulation of knowledge being a transversal resource of the various curricular areas, used according to the objectives of the lesson.

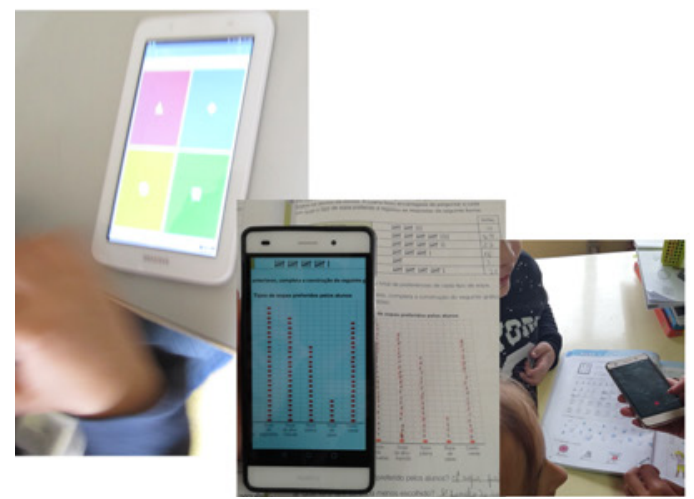

Fig. 3 The Smartphone as an instrument for consolidating curricular contents.

The exposed practices show the incorporation of the mobile nature, the connection with applications and the learning managed by the child. Thus, the mobile device served as a medium for the learning of children: (1) the QRCode Reader application to access: a) representative images of professions; b) texts that support relevant information to the lesson; c) questions guiding the understanding of a text; d) keywords for the development of a text; e) to links that guide the child to a safe page on the internet where he / she should read, to select information to carry out the task. Activities that stimulate autonomy, the know-how. (2) The Kahoot was used to consolidate knowledge and verify the learning of each student, in a playful way. Being interactive, it enables real-time feedback from the group response, stimulating immediate thinking, group collaboration, conflict management, coping with error, and the need to re-attempt to achieve results. (3) The voice recorder was used to record words to be reused autonomously by children. (4) Graph Maker lets you create charts or confirm results. Activities 2,3 and 4 stimulate the knowing how to be and be with others, autonomy, self-assessment and reflection on the acquired learning; (5) the camera and camcorder used to make a video / film allowed reflection on the participation of children and improved their performance. It also stimulated proactivity, critical reflection, argumentation, creativity, knowing how to be, being and doing. All the activities carried out show children's actions in the construction of knowledge by developing their own processes of acquisition of knowledge, feeling responsibilities for decisions that have immediate effects on their person and that of their colleagues, gaining an active understanding of the procedures that lead to success. It is understood why they captivate the student and the teacher.

\subsection{The smartphone in higher education}

Learning theories reveal that learning is more efficient when it is meaningful, engaging the student actively and emotionally, and puts him in direct contact with reality and with life, as Kolb points out [28]. The student learns by observing, reflecting on lived experience, actively experimenting and constructing abstract concepts through the manipulation of digital media. This allows the student to be able to know how to do in different situations, anticipating the effects of the action, since it mobilizes the theory in practice, transposes what he has learned to new situations, reflecting on the results and creating new solutions for future applications. It should be noted that, in the context of laboratory practices, computational simulations are often supported in experiential moments in order to develop more concrete learning opportunities. In fact, currently there are many simulation applications for electrical engineering running on mobile devices, so they are always available when the student needs them at any time and at any place, since they have access to them via the smartphone. 
In higher education the majority of students carry smartphones with them and no longer conceive life without them. According to the professor, simultaneously investigator, there are numerous applications that they use daily and that are adapted to the needs of each one. Thus, the smartphone allows access to information of the disciplinary areas available in the Moodle platform, to the institutional portal, online dictionaries and social networks, among others. With regard to its use as a classroom support resource, in addition to avoiding the physical transportation of manuals, technical books and bulky data sheets catalogues, as they are available online, students can easily access on their smartphone, scientific, graphical or programmable calculators, technical tables, tables of integral and derivatives, technical, theoretical and manufacturer sites, scientific articles, tutorial videos, lecture videos from reference universities, scientific and academic papers, thesis, exams and countless solved exercises. It was verified that the integration of all these tools in a single mobile device available to each student without occupying extra physical space, gives him better autonomy and promotes more fluency in the development of the class, since it allows the student to solve most of the difficulties that he would have, releasing the load of the teacher who is most available to guide and solve more complex problems. In addition, according to the teacher, "elementary concepts important in solving exercises and that were forgotten, can easily be searched on the Internet, available on a smartphone, and remembered by the student, without delays or embarrassment by questioning the colleagues or exposing themselves publicly in the classroom.

Also, the possibility of sharing information and collaboration with other students worldwide, either directly or through thematic discussion forums, allow to ask questions and respond to others in a synchronous and / or asynchronous process. "We are, therefore, facing a more autonomous and efficient student with greater opportunity to progress in the construction of his knowledge.

On the other hand, the smartphone, through the applications of simulation of electrical phenomena, in the test of assemblies of electrical circuits, implemented by the students, was used. In this sense, they easily checked the waveforms in the various points of the circuit (Fig. 4), they confronted the theoretical values of the simulation with the experimental values and they corrected any errors of assembly. It can be read in the field notes of the teacher that "they have been able to better understand the interaction between the electric quantities, besides to easily test changes to the circuit in the sense of optimization in view of the intended objectives.

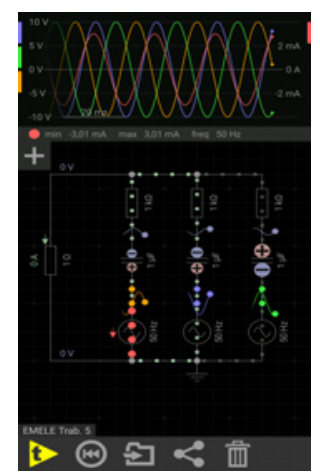

Fig. 4 The Smartphone as an engineering instrument of electrical simulation.

The use of the smartphone with these new possibilities of simulation, accessible in any moment at any time of their lives has created an increased enthusiasm, motivating them more towards the accomplishment of the tasks assigned".

Students often use their smartphones to access exercise books, as well as to photograph colleagues' notebooks when they miss classes or photograph the black/white board to quickly record exercise resolutions or theoretical explanations after kindly asking the teacher for permission (Fig. 5). 


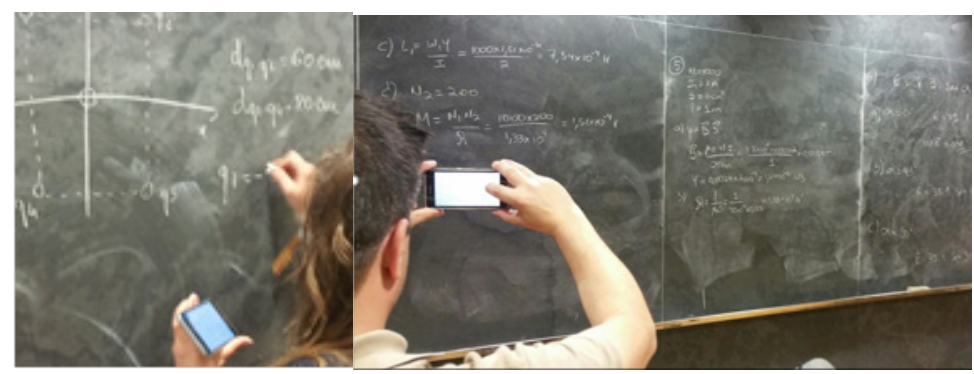

Fig. 5 The smartphone as an instrument of information access: consulting and registering.

The use of the smartphone in electrical engineering projects presents itself as a new opportunity, since they can monitor electrical quantities of equipment at a distance, allowing their monitoring and electrical isolation. In addition, Bluetooth communications over small distances, or over long distances over $\mathrm{Wi}-\mathrm{Fi}$ via the internet, creates new challenges, such as the possibility of remotely controlling equipment in different applications, such as the control of operating photovoltaics power stations in underdeveloped countries, control of drones, and others. In the specific case of the laboratory experience (Fig. 6), the smartphone was used to monitor and support the connection of an alternator in parallel with the mains, controlling the speed and voltage of the alternator in order to match the frequency and voltage of the alternator with the mains network.

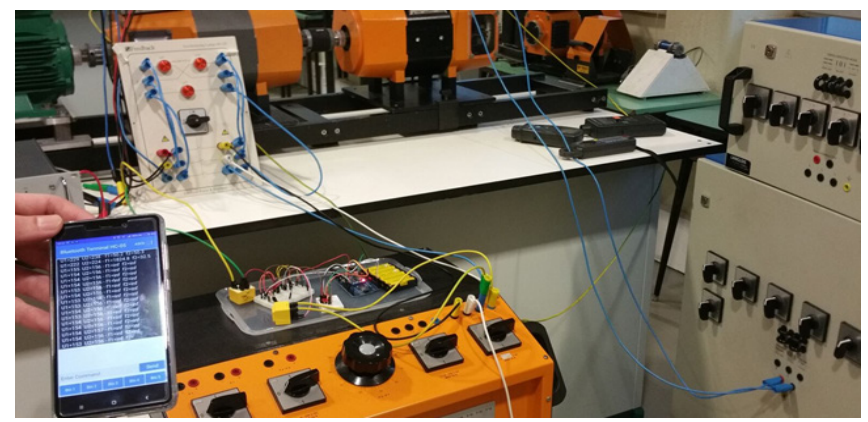

Fig. 6 The Smartphone as an instrument for remote monitoring and controlling projects.

Still, in words recorded in the notes of the teacher, "there was an increased enthusiasm and motivation among students, leading them to solve multidisciplinary challenges in the areas of electricity, electronics and software technology. It was gratifying to see the students' great satisfaction in completing the project using the mobile devices, in addition to recording the quantities in control, photographically and video record the various moments experienced and also the use of the same mobile equipment for sending and sharing with fellow friends and family of the lived experiences".

From the foregoing, it can be seen that the smartphone is also an added value in higher education. The students were able to observe and mobilize theoretical and practical knowledge by correcting tests and controlling the alternator's speeds and voltages; they were able to understand managing their own use, as well as stimulating collaboration and knowledge sharing, student autonomy concerning the access to information and its management in the classroom, making it more efficient and with better performance and, still allowed the management of emotions regarding difficult moments due to lack of information that could transmit a negative image of the student to his colleagues.

\section{CONCLUSION}

The size of the change begins to be significant. Learning the profession by looking at the practice involving mobile devices is now fundamental for the renewal of teaching professionalism. The exposed practices reveal that effectively the teacher is both a person and a professional [29] and that in a context of change personal capacities are fundamental: (1) flexibility to understand and adapt to the present and to prepare the future as an opportunity to respond to the social needs and interests of children and young students to generate constructive results and achieve common goals, as a strategic commitment to broaden horizons of professional achievement by highlighting the essence of being a teacher; (2) creativity as an imperative to architect new methodologies with new resources for 
a new generation with digital culture, to create new communication bridges that stimulate meaningful learning in a positive and enjoyable process in which the student manages his own learning taking advantage from the potential of the new educational resources, namely the flexibility of access to information and connection with others and things, satisfying needs and interests; (3) resilience in the sense of problem solving overcoming technical, methodological, relational and ethical obstacles.

As a synthesis, it was verified that the selection of the smartphone as a pedagogical resource in primary and higher education allowed teachers and students to articulate knowledge in a whole facilitator of the understanding of curricular and contextual contents. Also the adoption of a constructivist methodology, valuing the centrality of the student, involved him significantly in the dynamics of the classroom and in the learning process, inciting him to the autonomous, collaborative and responsible construction of his own knowledge. These are skills that today's society demands from its citizens, both in academic, professional, personal and civic life. In addition, the student's autonomy in relation to the learning process emphasizes his involvement by the use of the smartphone, because of its size, its accessibility character, student's personal, its potential for access to information and communication. Associated with an appropriate pedagogical methodology becomes a resource of great value in the education and motivation of the student.

\section{REFERENCES}

[1] J. Gikas and M. Grant, "Mobile computing devices in higher education: Student perspectives on learning with cellphones, smartphones \& social media," The and Higher education, vol. 19, pp. 18- 26, October 2013.

[2] B. Jeffreys, "Can a smartphone be a tool for learning?," Education \& Family, no. 29, September, 2015. Retrieved from http://www.bbc.com/news/education-34389063

[3] D. Odom, "Teaching with Smartphones in the Higher Education Classroom," The journal of Youth Ministry. vol. 14, no. 2, pp. 6 -15, Spring, 2016.

[4] Gomes et al. O Perfil dos alunos para o Séx XXI. G. Oliveira Martins (Coord.). Lisboa: Ministério da Educação, 2017. Retrieved from

https://dge.mec.pt/sites/default/files/Noticias_Imagens/perfil_do_aluno.pdf

[5] INTEF (2017). Marco Común de Competencias Digital Docente. Madrid: INTEF. Retrieved from http://educalab.es/documents/10180/12809/MarcoComunCompeDigiDoceV2.pdf

[6] J. Delors, Um tesouro a descobrir. Brasil: Unesco, 2010. [E-Reader Version]. Retrieved http://ftp.infoeuropa.eurocid.pt/database/000046001-000047000/000046258.pdf

[7] D. Schön, The reflective Practitioner: How Professionals Think in action. USA: Basic Books, Inc. 1983.

[8] J. Dewey, Experiência e educação (2 ${ }^{\mathrm{a}}$ Ed.). São Paulo: Companhia Editora Nacional, 1976.

[9] A. Latorre, La investigación-Acción. Barcelo: Graó, 2003.

[10] R. Carneiro, Fundamentos da Educação e da aprendizagem: 21 Ensaios para o séx. XXI. Vila Nova de Gaia: Fundação Manuel, 2003.

[11] M. Prensky, "Digital Natives, Digital Immigrants," in Horizon, vol. 9, no. 5, pp.1- 6, 2001.

[12] P. Flores and A. Ramos, "Práticas com TIC potenciadoras de mudança," in 1. ${ }^{\circ}$ Encontro Internacional de Formação na Docência (INCTE), pp.195-203, Bragança: Instituto Politécnico. [E-Reader Version]. Retrieved https://bibliotecadigital.ipb.pt/handle/10198/11435

[13] N. Carr (2012). Os Superficiais: O que a internet está a fazer aos nossos cérebros. Lisboa: Gradiva.

[14] A, Froese C. Carpenter, D. Inman, J. Schooley, R. Barnes, P. Brecht, and J. Chacon, "Effects of classroom cell phone use on expected and actual learning," in College Student Journal, 2012. vol. 46, no. 2, pp. 323-332, 2012.

[15] C. Tossell, P. Kortum, C. Shepard, A.Rahmati and L. Zhong, "You can lead a horse to water but you cannot make him learn: Smartphone use in higher education," British Journal of Educational Technology, vol 46, no. 4, pp. 713-724, 2015. 
[16] Aharony, N. "Librarians' attitudes towards mobile services," Aslib Proceedings, vol. 65, no. 4, pp. 358-375, 2013. [E-Reader Version] Retrieved from http://dx.doi.org/10.1108/ap-07-20120059

[17] D. Parmigiani and M. Giusto, "Using smartphones and tablets in higher education contexts: na exploratory study within a teacher education program," in REM - Research on Education and Media, 2016. vol. 8, no. 1, ISSN: 2037-0830. Available in https://www.degruyter.com/view/j/rem.2016.8.issue-1/rem-2016-0002/rem-2016-0002.xml

[18] E. Vázquez-Cano and M. García, "El smartphone en la educación superior. Un estudio comparativo del uso educativo, social y ubicuo en universidades españolas e hispanoamericanas," Signo y Pensamiento, vol. XXXIV, no. 67, pp 132- 149. 2015.

[19] A. Moura. Nativos Digitais - Telemóvel: o e-Caderno, 2012. Retrieved https://www.youtube.com/watch?v=XOvlzaqOTjl

[20] A. Moura. Apropriação do Telemóvel como Ferramenta de Mediação em Mobile Learning: Estudo de casos em contextos educativo. Tese de doutoramento da Universidade do Minho, 2010. Retrieved from https://repositorium.sdum.uminho.pt/bitstream/1822/13183/1/Tese\%20Integral.pdf

[21] A. A. Carvalho and I. Araújo, "Dispositivos móveis mais utilizados por alunos de $3^{\circ} \mathrm{CEB}$ para jogar," Simpósio Internacional de Informática Educativa. Viseu. Vol. XV. Retrieved from https://www.researchgate.net/publication/258516031_Dispositivos_moveis_mais_utilizados_por _alunos_do_3_CEB_para_jogar

[22] E. Klopfer, "Resonant Games - Designing educational games that resonate in the lives of students, teachers and schools," in Atas do 3. Encontro sobre Jogos e Mobile Learning (A. Carvalho et al, eds.), pp.15-16, Coimbra: Universidade de Coimbra. [E-Reader Version] Retrieved from ISBN: 978-972-95595-9-4 (2016).

[23] M. A Marconi,. \& E. M Lakatos.. Fundamentos da Metodologia Científica. São Paulo: Atlas, 2007.

[24] J. Werthein, "Apresentação da edição brasileira", in Os sete saberes necessários à educação do futuro (2 ${ }^{\mathrm{a}}$ ed.), pp. 11-12, Brasília: UNESCO, Cortez Editora, 2000.

[25] E. Morin, Os sete saberes necessários à educação do futuro (2a ed.). Brasília: UNESCO, Cortez Editora, 2000.

[26] P. Feliciano, "(Trans)Formação ao longo da vida: um lugar de mudança e desenvolvimento". Dirigir \& Formar, no. 14. jan-,março 2017.

[27] LBSE, Lei n. ${ }^{\circ}$ 46/86, de 14 de Outubro de 1986, Lei de Bases do Sistema educativo. Ministério da Educação, Lisboa,1986.

[28] D. Kolb, Experimential Leraning: experience as The Source of Learning and development. New Jersev: Prentice-Hall, Inc. Englewood Cliffs, 1984.

[29] J. Nias, "Changing Times, Changing Identities: Grieving for a Lost Self", Educational Research and Evaluation [ed. R. Burgess]. Lewes: The Falmer Press, 1991. 